\title{
Effect of Spacing and Periodical Staggered Nipping on Botrytis Disease Incidence and Quality of Castor (Ricinus communis L.)
}

\author{
K. Sunil Kumar ${ }^{1^{*}}$ and H.S. Shivaramu ${ }^{2}$ \\ ${ }^{1}$ UAS, Dharwad, Karnataka, India \\ ${ }^{2}$ Department of Agrometeorology, UAS, Bengaluru, Karnataka, India \\ *Corresponding author
}

\section{A B S T R A C T}

The field experiment was conducted during the kharif seasons of 2013 and 2015 at ZARS,

\section{Keywords}

Castor, Spacing, Nipping, Botrytis

Article Info

Accepted:

22 October 2018

Available Online:

10 November 2018

University of Agricultural Sciences, Gandhi Krishi Vigyan Kendra, Bengaluru on red sandy clay loam soil to know the influence of periodical staggered nipping and spacing on Botrytis disease infestation and quality of castor. Nipping and different spacing's in castor significantly influenced the disease incidence and castor oil yield. Periodical staggered nipping leaving one spike in each branch recorded lower Botrytis disease scoring (2.71) and chaffiness $(6.43 \%)$ as compared to non-nipping treatments. This treatment also recorded significantly higher oil content $(44.34 \%)$ and oil yield $\left(7.75 \mathrm{q} \mathrm{ha}^{-1}\right)$. Among the different spacing levels lower Botrytis disease scoring (3.17), chaffiness $(11.61 \%)$ and significantly higher oil content $(44.29 \%)$ were noticed with the spacing of $120 \times 45 \mathrm{~cm}$. Whereas, significantly higher oil yield was recorded in the spacing of $90 \times 45 \mathrm{~cm}(6.91 \mathrm{q}$ $\mathrm{ha}^{-1}$ ). Interaction effects between periodical staggered nipping and spacing were not significant.

\section{Introduction}

Among oilseeds, castor (Ricinus communis L.) is the most primitive non-edible crop belonging to family Euphorbiaceae grown under tropical, sub-tropical and temperate regions. Seeds of this crop were found during excavation in Egypt, Sudan, India and in ancient agricultural dwellings of North West Asia and Iran. Evidences indicate that the crop was originated in Ethiopia (Weiss, 1971) and in India (Moshkin, 1986). Its cultivation is spread over thirty countries of the world. India, Mozambique, China, Brazil, Angola, Philippines and Thailand are the leading countries and producing nearly 85 per cent of the total castor production of the world. As a non-edible and industrial crop, castor plays an important role in Indian economy because of better export potential. During 2014-15, the country earned a foreign exchange worth of ₹ 4364.33 crores through export of castor oil and cake (Anon, 2015).

The castor plant being perennial in nature is capable of producing branches from every auxillary bud that appears on its main axis. The lower shoots that develop from the auxillary buds many a times produce spikes not as much effective as main spike. Nutrition 
to the lower branches thus gets wasted resulting in weaker spikes of short length, high susceptibility to diseases, particularly Bortytis, thus resulted in chaffiness, poor seed weight and lower yield (Patel et al., 1976). In castor, maintenance of source to sink relationship is very important rather than allowing more vegetative growth presumably for higher yields. Hence, staggered nipping i.e., removal of auxillary buds assumes importance in maintaining optimum source to sink relationship. Keeping this in view, an attempt has been made in present study to find out the impact of staggered nipping and different spacing on Botrytis disease incidence and quality of castor.

\section{Materials and Methods}

The field experiment was conducted during the kharif seasons of 2013 and 2015 at ZARS, University of Agricultural Sciences, Gandhi Krishi Vigyan Kendra, Bengaluru on red sandy clay loam soil. The soils were medium in available nitrogen $\left(295.5 \mathrm{~kg} \mathrm{ha}^{-1}\right)$, available phosphorus (34.20 kg ha $\mathrm{kg}^{-1}$ and available potassium (155.75 $\left.\mathrm{kg} \mathrm{ha}^{-1}\right)$. The organic carbon $(0.51 \%)$ content was also medium. The experiment was laid out in Randamized Complete Block Design consisting of three levels of spacing $(60 \times 45 \mathrm{~cm}, 90 \times 45 \mathrm{~cm}$ and $120 \times 45 \mathrm{~cm}$ ) and nipping (no nipping, periodical staggered nipping leaving one spike in each branch and periodical staggered nipping leaving two spikes in each branch) and replicated thrice. The recommended dose of 38:38:25 kg NPK and 5t of FYM ha ${ }^{-1}$ was given to castor. Intercultivation and weeding were done to keep the weeds under check. Need based plant protection was followed to control sucking insects. Staggered nipping in case of castor is a selective removal of nodal buds at regular intervals. The methodology includes nipping of all the nodal buds in the primary stem except the one just below the primary spike immediately after the emergence of primary spike. The secondary branch emerging just below the primary spike is allowed to grow and it ends with a spike at the tip. Then all the nodal buds of the secondary branch will be nipped-off except the one below the secondary spike. All the nodes of tertiary branch will be nipped-off except the one below the tertiary spike. In the same way one quaternary, penta and hexa branches and spikes will be allowed respectively. It is done in the experiment according to the different nipping treatments (Fig. 1). After periodical harvesting the spikes, capsules were dried and threshed. Seed yield and stalk yield in each plot was recorded and analysed statistically.

\section{Botrytis disease scoring}

Gray mould (Botrytis ricini) is a major disease in castor infecting flowers and capsules. The extent of damage goes even up to 85 per cent depending on the humidity. Night temperatures below $22{ }^{\circ} \mathrm{C}$ followed by rains are highly favourable for the spread of disease (Diraviam, 2006). The severity of Botrytis disease was assessed by adopting 1-9 scale (Subramanyam et al., 1982) as given below.

\section{Scale: Per cent of infestation}

0: No incidence

1: 1 per cent of capsule infected

3: 2-10 per cent of capsule infected

5: 11-25 per cent of capsule infected

7: $26-50$ per cent of capsule infected

9: $>50$ per cent of capsule infected

\section{Results and Discussion}

\section{Effect of spacing}

Spacing has significant influence on Botrytis diseases and chaffiness of castor. The incidence of disease was observed maximum in the lower spacing. 


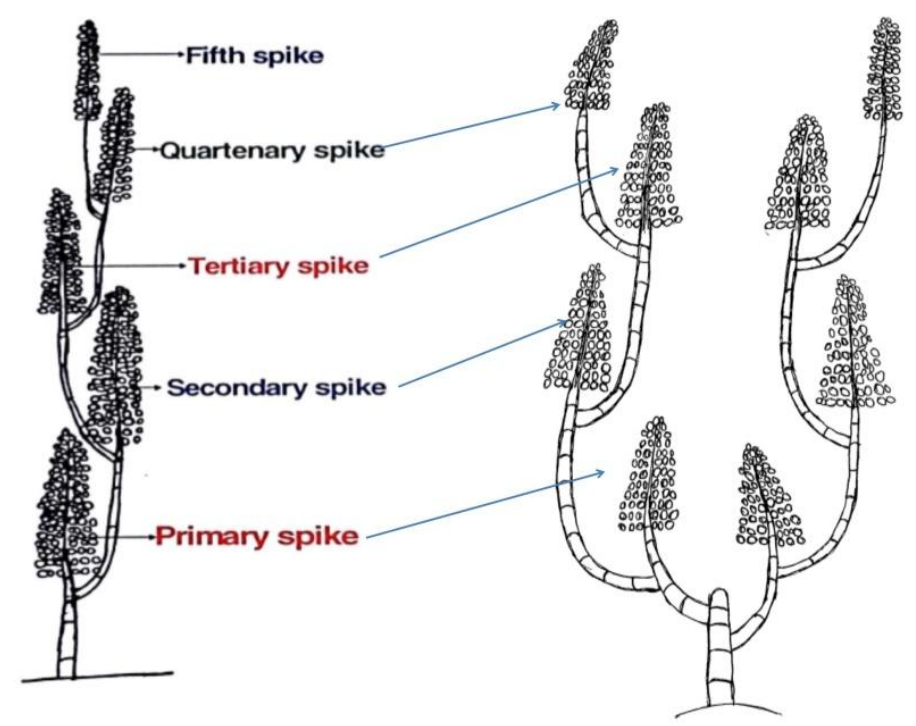

Fig. 1: a) Nipping leaving one spike b) Nipping leaving two spike

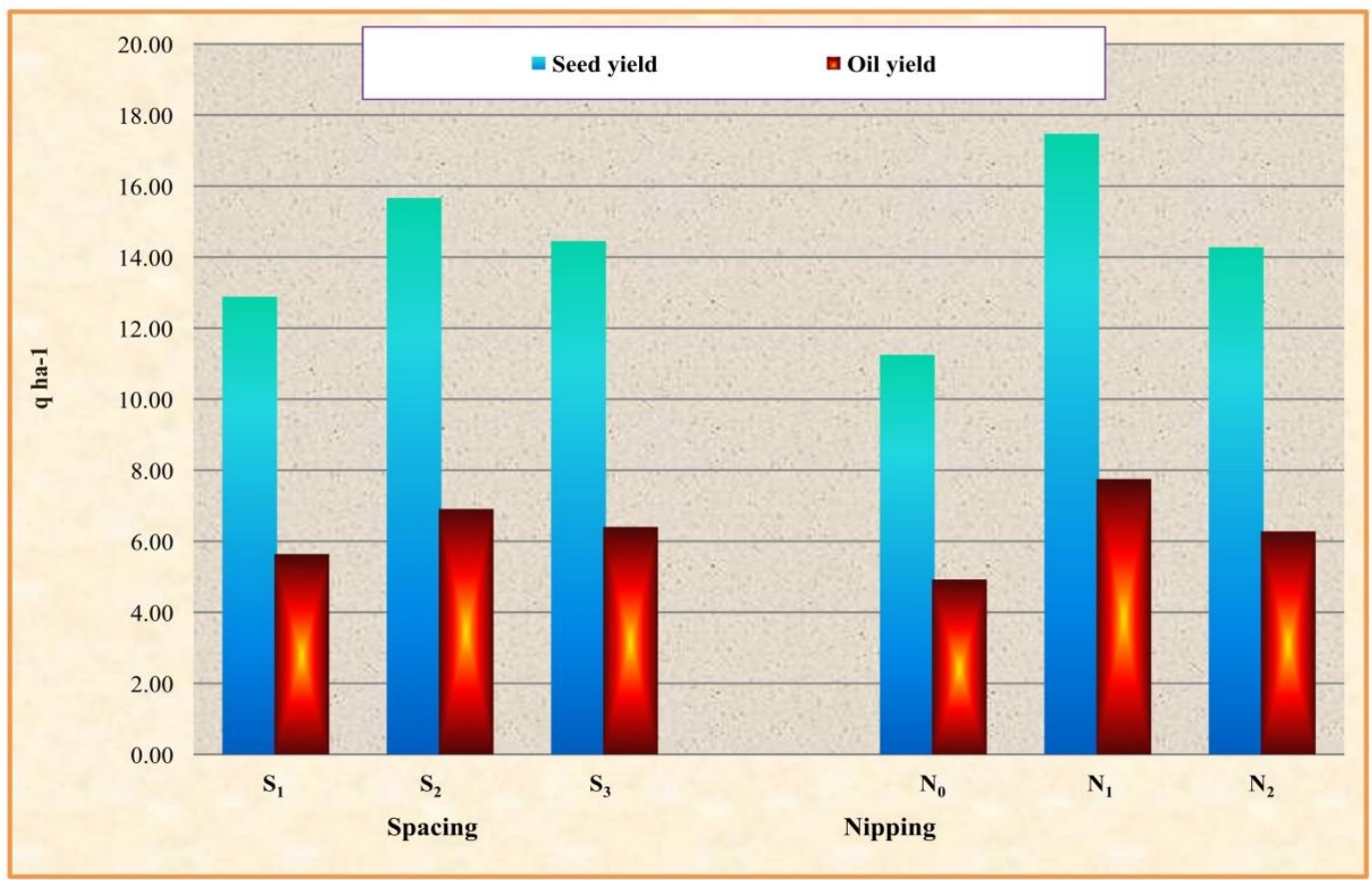

Fig. 2: Seed yield and oil yield of castor as influenced by spacing and nipping 


\section{Int.J.Curr.Microbiol.App.Sci (2018) 7(11): 2822-2828}

Table.1 Botrytis disease scoring (0-9 Scale) study in castor at different pickings as influenced by spacing and nipping

\begin{tabular}{|c|c|c|c|c|c|c|c|c|c|c|c|c|}
\hline \multirow[t]{2}{*}{ Treatment } & \multicolumn{3}{|c|}{$1^{\text {st }}$ picking } & \multicolumn{3}{|c|}{$2^{\text {nd }}$ picking } & \multicolumn{3}{|c|}{$3^{\text {rd }}$ picking } & \multicolumn{3}{|c|}{ Overall mean } \\
\hline & 2013 & 2015 & Pooled & 2013 & 2015 & Pooled & 2013 & 2015 & Pooled & 2013 & 2015 & Pooled \\
\hline \multicolumn{13}{|l|}{ Spacing (S) } \\
\hline$S_{1}: 60 \times 45 \mathrm{~cm}$ & 3.74 & 5.09 & 4.42 & 4.08 & 5.42 & 4.75 & 4.32 & 5.51 & 4.92 & 4.05 & 5.34 & 4.69 \\
\hline$S_{2}: 90 \times 45 \mathrm{~cm}$ & 2.73 & 4.31 & 3.52 & 3.33 & 4.96 & 4.14 & 3.41 & 5.01 & 4.21 & 3.16 & 4.76 & 3.96 \\
\hline$S_{3}: 120 \times 45 \mathrm{~cm}$ & 2.24 & 3.23 & 2.74 & 2.84 & 3.78 & 3.31 & 3.03 & 3.89 & 3.46 & 2.71 & 3.63 & 3.17 \\
\hline \multicolumn{13}{|l|}{ Nipping $(\mathbf{N})$} \\
\hline $\mathbf{N}_{\mathbf{0}}$ & 4.07 & 5.79 & 4.93 & 4.46 & 6.44 & 5.45 & 4.69 & 6.54 & 5.62 & 4.40 & 6.26 & 5.33 \\
\hline $\mathbf{N}_{1}$ & 1.84 & 2.79 & 2.32 & 2.46 & 3.27 & 2.86 & 2.57 & 3.33 & 2.95 & 2.29 & 3.13 & 2.71 \\
\hline $\mathbf{N}_{2}$ & 2.81 & 4.06 & 3.43 & 3.34 & 4.44 & 3.89 & 3.51 & 4.53 & 4.02 & 3.22 & 4.34 & 3.78 \\
\hline \multicolumn{13}{|c|}{ Interactions (S X N) } \\
\hline $\mathbf{S}_{1} \mathbf{N}_{\mathbf{0}}$ & 4.93 & 7.13 & 6.03 & 5.03 & 7.57 & 6.30 & 5.40 & 7.70 & 6.55 & 5.12 & 7.47 & 6.29 \\
\hline $\mathbf{S}_{1} \mathbf{N}_{1}$ & 2.63 & 3.53 & 3.08 & 3.07 & 3.80 & 3.43 & 3.17 & 3.87 & 3.52 & 2.96 & 3.73 & 3.34 \\
\hline $\mathbf{S}_{\mathbf{1}} \mathbf{N}_{\mathbf{2}}$ & 3.67 & 4.60 & 4.13 & 4.13 & 4.90 & 4.52 & 4.40 & 4.97 & 4.68 & 4.07 & 4.82 & 4.44 \\
\hline $\mathbf{S}_{2} \mathbf{N}_{0}$ & 4.00 & 6.07 & 5.03 & 4.57 & 7.03 & 5.80 & 4.60 & 7.10 & 5.85 & 4.39 & 6.73 & 5.56 \\
\hline $\mathbf{S}_{2} \mathbf{N}_{1}$ & 1.67 & 2.73 & 2.20 & 2.33 & 3.23 & 2.78 & 2.43 & 3.27 & 2.85 & 2.14 & 3.08 & 2.61 \\
\hline $\mathbf{S}_{2} \mathbf{N}_{2}$ & 2.53 & 4.13 & 3.33 & 3.10 & 4.60 & 3.85 & 3.20 & 4.67 & 3.93 & 2.94 & 4.47 & 3.71 \\
\hline $\mathbf{S}_{\mathbf{3}} \mathbf{N}_{\mathbf{0}}$ & 3.27 & 4.17 & 3.72 & 3.77 & 4.73 & 4.25 & 4.07 & 4.83 & 4.45 & 3.70 & 4.58 & 4.14 \\
\hline $\mathbf{S}_{3} \mathbf{N}_{1}$ & 1.23 & 2.10 & 1.67 & 1.97 & 2.77 & 2.37 & 2.10 & 2.87 & 2.48 & 1.77 & 2.58 & 2.17 \\
\hline $\mathbf{S}_{3} \mathbf{N}_{2}$ & 2.23 & 3.43 & 2.83 & 2.80 & 3.83 & 3.32 & 2.93 & 3.97 & 3.45 & 2.66 & 3.74 & 3.20 \\
\hline
\end{tabular}


Table.2 Chaffiness percentage, oil content and oil yield of castor as influenced by spacing and nipping

\begin{tabular}{|c|c|c|c|c|c|c|c|c|c|}
\hline \multirow[t]{2}{*}{ Treatment } & \multicolumn{3}{|c|}{ Chaffiness (\%) } & \multicolumn{3}{|c|}{ Oil content (\%) } & \multicolumn{3}{|c|}{ Oil yield $\left(q h^{-1}\right)$} \\
\hline & 2013 & 2015 & Pooled & 2013 & 2015 & Pooled & 2013 & 2015 & Pooled \\
\hline \multicolumn{10}{|l|}{ Spacing $(\mathbf{S})$} \\
\hline$S_{1}: 60 \times 45 \mathrm{~cm}$ & 21.17 & 17.82 & 19.49 & 43.38 & 44.11 & 43.74 & 5.32 & 5.96 & 5.64 \\
\hline$S_{2}: 90 \times 45 \mathrm{~cm}$ & 15.98 & 13.64 & 14.81 & 43.80 & 44.29 & 44.04 & 6.58 & 7.24 & 6.91 \\
\hline$S_{3}: 120 \times 45 \mathrm{~cm}$ & 12.67 & 10.54 & 11.61 & 44.02 & 44.56 & 44.29 & 6.18 & 6.63 & 6.41 \\
\hline S. Em. \pm & 0.51 & 0.45 & 0.42 & 0.10 & 0.11 & 0.06 & 0.22 & 0.23 & 0.18 \\
\hline C. D. at $5 \%$ & 1.52 & 1.36 & 1.26 & 0.29 & 0.32 & 0.19 & 0.65 & 0.69 & 0.53 \\
\hline \multicolumn{10}{|l|}{ Nipping (N) } \\
\hline $\mathbf{N}_{0}$ & 27.39 & 23.19 & 25.29 & 43.49 & 44.04 & 43.77 & 4.71 & 5.14 & 4.93 \\
\hline $\mathbf{N}_{1}$ & 6.97 & 5.90 & 6.43 & 44.07 & 44.62 & 44.34 & 7.38 & 8.12 & 7.75 \\
\hline $\mathbf{N}_{2}$ & 15.46 & 12.92 & 14.19 & 43.64 & 44.29 & 43.97 & 5.98 & 6.58 & 6.28 \\
\hline S. Em. \pm & 0.51 & 0.45 & 0.42 & 0.10 & 0.11 & 0.06 & 0.22 & 0.23 & 0.18 \\
\hline C. D. at $5 \%$ & 1.52 & 1.36 & 1.26 & 0.29 & 0.32 & 0.19 & 0.65 & 0.69 & 0.53 \\
\hline \multicolumn{10}{|c|}{ Interactions (S X N) } \\
\hline $\mathbf{S}_{\mathbf{1}} \mathbf{N}_{0}$ & 32.60 & 27.73 & 30.17 & 43.20 & 43.90 & 43.55 & 4.13 & 4.49 & 4.31 \\
\hline $\mathbf{S}_{1} \mathbf{N}_{1}$ & 9.60 & 8.40 & 9.00 & 43.67 & 44.33 & 44.00 & 6.78 & 7.46 & 7.12 \\
\hline $\mathbf{S}_{1} \mathbf{N}_{2}$ & 21.30 & 17.33 & 19.32 & 43.27 & 44.10 & 43.68 & 5.05 & 5.93 & 5.49 \\
\hline $\mathbf{S}_{2} \mathbf{N}_{0}$ & 26.43 & 22.57 & 24.50 & 43.50 & 44.03 & 43.77 & 5.11 & 5.43 & 5.27 \\
\hline $\mathbf{S}_{2} \mathbf{N}_{1}$ & 6.57 & 5.23 & 5.90 & 44.17 & 44.60 & 44.38 & 8.11 & 9.19 & 8.65 \\
\hline $\mathbf{S}_{2} \mathbf{N}_{2}$ & 14.93 & 13.13 & 14.03 & 43.73 & 44.23 & 43.98 & 6.52 & 7.11 & 6.81 \\
\hline $\mathbf{S}_{3} \mathbf{N}_{0}$ & 23.13 & 19.27 & 21.20 & 43.77 & 44.20 & 43.98 & 4.90 & 5.49 & 5.20 \\
\hline $\mathbf{S}_{\mathbf{3}} \mathbf{N}_{1}$ & 4.73 & 4.07 & 4.40 & 44.37 & 44.93 & 44.65 & 7.25 & 7.71 & 7.48 \\
\hline $\mathbf{S}_{3} \mathbf{N}_{2}$ & 10.13 & 8.30 & 9.22 & 43.93 & 44.53 & 44.23 & 6.38 & 6.69 & 6.54 \\
\hline S. Em. \pm & 0.88 & 0.78 & 0.73 & 0.17 & 0.19 & 0.11 & 0.38 & 0.40 & 0.31 \\
\hline C. D. at $5 \%$ & 2.64 & NS & 2.19 & NS & NS & NS & NS & NS & NS \\
\hline $\mathrm{CV} \%$ & 9.17 & 9.70 & 8.26 & 0.67 & 0.73 & 0.44 & 10.81 & 10.42 & 8.40 \\
\hline $\mathrm{N}_{0}$ : No nipping & pping lea & one spik & ach branch & $\mathrm{N}_{2}: \mathrm{N}$ & ng leavin & spikes in & ranch & NS: Non & iificant \\
\hline
\end{tabular}


Spacing of $120 \times 45 \mathrm{~cm}$ recorded minimum disease scoring (3.17) and chaffiness (11.61 $\%)$ as compared to $90 \times 45 \mathrm{~cm}$ (3.96 and $14.81 \%$, respectively) and $60 \times 45 \mathrm{~cm}(4.69$ and $19.49 \%$, respectively) (Table 1 and 2). The lower plant spacing resulted higher plant population attributed to canopy overlapping and shading. Thicker plant density along with prolonged humid conditions coupled with continuous rainfall with cloudy weather leads to severe infestation of spikes with Botrytis disease. The results are inconformity with the findings of Patel et al., (1976).

Significant difference in oil content was noticed among the different spacings. Spacing of $120 \times 45 \mathrm{~cm}$ recorded significantly higher oil content (44.29\%) as compared to $90 \times 45$ $\mathrm{cm}(44.04 \%)$ and $60 \times 45 \mathrm{~cm}(43.74 \%)$. The higher yield attributing parameters were achieved due to better growth and growth components, which helped in better uptake of nutrients and better translocation of photosynthates from source to sink lead to higher oil content in seeds. These results are in conformity with the findings of Porwal et al., (2006) and Rana et al., (2006). Oil yield was found to be significant among the spacings. Significantly higher oil yield was recorded in $90 \times 45 \mathrm{~cm}$ (6.91 q ha $\mathrm{qa}^{-1}$ ) as compared to other two spacings (Table 2). This might be attributed to higher yield and yield attributing parameters in this row spacing (Fig. 2).

\section{Effect of staggered nipping}

The severity of Botrytis disease infestation of spikes was more in non-nipped plots compared to periodical staggered nipping plots. The lower incidence of Botrytis disease noticed in nipping leaving one spike in each branch with disease scoring of 2.71 as against 5.33 in non-nipped plot and 3.78 in nipping leaving two spikes in each branch (Table 1). This might be due to crowded canopy coverage, humidity in the microclimate and canopy overlapping with less light penetration as compared to nipping plots.

Lower percentage of chaffiness was recorded in nipping leaving one spike in each branch (6.43\%) and nipping leaving two spikes in each branch $(14.19 \%)$ as against 25.29 per cent in non-nipped (Table 2). The increased disease severity and higher percentage of chaffiness under non-nipping conditions of castor are in agreement with the findings of Venkate Gowda et al., (2011) and Shivaramu and Krishna Murthy (2008).

Significantly higher oil content was recorded in nipping of castor leaving one spike in each branch $(44.34 \%)$ as compared to that in nonipping (43.77\%) and nipping leaving two spikes in each branch (43.97 \%). This treatment also recorded significantly higher oil yield $\left(7.75 \mathrm{q} \mathrm{ha}^{-1}\right)$. The oil yield is the resultant of oil content of seeds and seed yield of the crop. Higher oil content and higher seed yield of castor obtained from nipped treatments resulted in higher oil yield over non-nipping treatments (Table 2 and Fig. 2).

These results are in conformity with the findings of VenkateGowda et al., (2011) and Shivaramu and Krishna Murthy (2008). Interaction effects of both spacing and periodical staggered did not showed any significant effect on disease incidence, chaffiness, oil content, oil yield and seed yield.

Thus, the wider spacing of castor planting at $120 \times 45 \mathrm{~cm}$ along with nipping leaving one spike in each branch found better for reducing the disease infestation and chafiness whereas, castor with spacing of $90 \times 45 \mathrm{~cm}$ along with nipping leaving one spike in each branch found better for oil yield and seed yield under dryland conditions of the Eastern Dry Zone of Karnataka. 


\section{References}

Anonymous, 2015. www.indiastat.com

Diraviam, J., 2006. Guidelines for IPM of major crops on the Deccan plateaubasket of options. Pp. 29-30.

Moshkin, V.A., 1986. Castor. Oxonian press (Pvt.) Ltd., Pp. 1-10.

Patel, P.K., Vaishnavi, N.L. and Patel, B.R., 1976. Nipping of branches increases yield in castor. Indian Farming, 26: 3435.

Porwal, M.K., Agarwal, S.K. and Khokhar, A.K., 2006. Effect of planting methods and intercrops on productivity and economics of castor-based intercropping system. Indian Journal of Agronomy, 51(4): 274-277.

Rana, D.S., Giri, G. and Panchuri, D.K., 2006. Evaluation of castor genotypes for productivity, economics, litter fall and changes in soil properties under different levels of intra-row spacing and nitrogen. Indian Journal of Agronomy. 51(4): 318-322.

Shivaramu, H. S. and Krishna Murthy, D., 2008. Staggered nipping in castor planted with different dates of sowing under dryland conditions. Mysore Journal of Agricultural Sciences. 42(4): 776-779.

Subramanyam, P., Donald, N., Gibbons, R.W., Nigam, S.N. and Nevile, D.S., 1982. Peanut Sci., 9: 6-10.

VenkateGowda, J., Shivaramu, H. S., Krishna Murthy, N., Ravi Kumar, H. S. and Manjunatha, B. N., 2011. Effect of nipping and dates of sowing on growth, yield and disease infestation of castor genotypes. International Journal of Forestry and Crop Improvement, 2(1): 73-77.

Weiss, E.A., 1971, Castor, sesame and sunflower. Leonard Hill, London, Pp. 31-99.

\section{How to cite this article:}

Sunil Kumar, K. and Shivaramu, H.S. 2018. Effect of Spacing and Periodical Staggered Nipping on Botrytis Disease Incidence and Quality of Castor (Ricinus communis L.). Int.J.Curr.Microbiol.App.Sci. 7(11): 2822-2828. doi: https://doi.org/10.20546/ijcmas.2018.711.325 